\title{
Dos proyectos identitarios para América Latina: José Enrique Rodó (1871-1917) y Nimio de Anquín (1896-1979)
}

Inés Achával Becú ${ }^{1}$

Resumen: La indagación en torno a la identidad de América Latina y el problema del desarrollo del continente, ha sido una cuestión central en el pensamiento latinoamericano, que informó las representaciones, discursos y prácticas de los actores político-sociales a lo largo del siglo XX. Desde esta perspectiva, este trabajo se propone resaltar los rasgos de continuidad en las posturas identitarias desde principios de siglo, realizando una aproximación de tipo comparativo entre dos intelectuales que marcaron dos épocas en el pensamiento latinoamericano y que sentaron las bases para desarrollos ulteriores: el uruguayo José Enrique Rodó (1871-1917) y el filósofo argentino Nimio de Anquín (1896-1979). El trabajo analiza para ello las dos obras representativas de ambos autores: Ariel (1900) de J. Rodó y Mito y Política (1955), de Nimio de Anquín.

Palabras claves: identidad latinoamericana - antiimperialismo - José E. Rodó - Nimio de Anquín - democracia liberal

\begin{abstract}
The inquiry about the identity of Latin America and the continent's development problems, has been a central issue in Latin American thought, which reported the representations, discourses and practices of socio-political actors throughout the twentieth century. From this perspective, this paper highlights the features of continuity in identity positions since the beginning of the century, making a comparative approach between two types of intellectuals who marked two periods in Latin American thought and laid the groundwork for further developments: the uruguayan Jose Enrique Rodo (1871-1917) and the argentine philosopher Nimio de Anquin (1896-1979). This paper analyzes the two representative works of both authors: Ariel (1900) de J. Rodo and Myth and Politics (1955), of Nimio de Anquin.
\end{abstract}

\footnotetext{
${ }^{1}$ Centro de Estudios Históricos "Prof. Carlos S. A. Segreti" Unidad Asociada Conicet-Argentina. E-mail: inesachaval@hotmail.com
}

Revista Eletrônica da ANPHLAC, n.13, p. 204-226, jul./dez. 2012. http://revista.anphlac.org.br/index.php/revista 
Key words: latin american identity - anti-imperialism - José E. Rodó - Nimio de Anquín - liberal democracy

\section{Introducción}

La indagación en torno a la identidad de América Latina y el problema del desarrollo del continente ha sido una cuestión central en el pensamiento latinoamericano, que informó las representaciones, discursos y prácticas de los actores político-sociales a lo largo del siglo XX y que aún sigue siendo una cuestión central por la necesidad de consolidar una integración en un proceso de globalización creciente. Ante ese proceso, desde finales del siglo XX e inicios del tercer milenio, se operó en muchos países de la región un fenómeno de resistencia, reforzamiento, revalorización y movilización de carácter identitario en reacción y oposición a un paradigma neoliberal. Estas nuevas movilizaciones acontecidas tienen como antecedentes de larga duración en la historia de América Latina, el desarrollo de un pensamiento identitario que posibilitó y acompañó las innumerables y heterogéneas movilizaciones contra lo que se consideraba el intento de modernización extranjerizante. Como afirma Eduardo Devés Valdéz, "el pensamiento latinoamericano es la historia de los intentos explícitos o implícitos por armonizar modernización e identidad" (DEVÉS VALDÉS, 2000, p. 13). Ambas posturas mantienen una tensa disputa en donde cada ciclo identitario parte de una nueva etapa de modernización que se rechaza, pero de la cual se parte (DEVÉS VALDÉS, 2000, p. 9). Desde esta perspectiva, este trabajo se propone resaltar las continuidades de las posturas identitarias desde principios de siglo, realizando una aproximación de tipo comparativo entre dos intelectuales que marcaron dos épocas en el pensamiento latinoamericano y que sentaron las bases para desarrollos ulteriores: el uruguayo José Enrique Rodó (1871-1917) y el filósofo argentino Nimio de Anquín (1896-1979).

Metodológicamente se comparan las posturas de ambos pensadores a partir de dos obras: Ariel (1900) (RODÓ, 1960) de José Rodó y Mito y Política (1955) (DE ANQUIN, Nimio, 1956) de Nimio de Anquín, único ensayo en el que el filósofo cordobés vuelca sus ideas políticas. Ambos intelectuales plantearon propuestas que son 
comparables -a pesar de los más de cincuenta años de diferencia entre cada obra-, por compartir ciertas características comunes de todos los proyectos identitarios, como la reivindicación y defensa de lo americano, de lo latino, de lo propio; la valoración de lo cultural, lo artístico, lo humanista en desmedro de lo tecnológico; la crítica al intervencionismo extranjero en América Latina, la reivindicación de la independencia y la liberación; la acentuación de la justicia; la reivindicación de un ser latinoamericano propio que se fundamenta en lo espiritual y cultural (DEVÉS VALDÉS, 2000, p. 18).

En este trabajo se combina la clasificación de los intelectuales a partir del concepto de generación que facilita la ubicación histórica de los individuos en una cronología, con un enfoque sociocultural y político que permite resaltar el contexto histórico de producción de las obras, los problemas y temas compartidos en el clima cultural de la época, pero también la circulación de las ideas en la larga duración, destacando lo que cada generación comparte con otras que las preceden y que las continúan, posibilitando las continuidades y transformaciones de los problemas. Por ello, si bien esta aproximación intenta resaltar las continuidades o similitudes entre ambos proyectos, es preciso historizar y contextualizar cada reclamo de identidad que adquiere matices epocales (DEVÉS VALDÉS, 2000, p.10). De acuerdo a las diferencias del contexto, de los tiempos y de las posturas ideológicas, se acentúan algunos puntos por sobre otros o se diferencian en el sentido de los mismos.

El trabajo en primera instancia, plantea las condiciones históricas de producción de los proyectos de ambos intelectuales y con posterioridad se analizarán las obras, a partir de tres ejes articuladores: el primero es el problema del imperialismo de los Estados Unidos y la imitación cultural; el segundo eje es el tópico de la democracia, y el tercero, los proyectos latinoamericanos de J. Rodó y Nimio de Anquín como respuestas al desafío del imperialismo.

\section{José Enrique Rodó y Nimio de Anquín: condiciones históricas de producción de dos proyectos identitarios}

La figura de José Rodó es central y su ensayo Ariel es un emblema, que no solo marca una inflexión en el desarrollo del pensamiento latinoamericano, sino que funciona como un catalizador de los pensadores que ante similares inquietudes y 
disconformes con el proyecto modernizador y positivista, venían produciendo obras en todo el continente de forma simultánea. Esto ayudó a la expansión del arielismo como sensibilidad general y fomentó un ciclo identitario durante las primeras décadas del siglo $\mathrm{XX}$ en el que se buscaba lo específico hispanoamericano como primer acercamiento a la idea de América con contenido propio. Como antecedentes de esta preocupación por no transplantar ideas o instituciones extranjeras -especialmente las imitaciones norteamericanas- que se catalogaban como ajenas a lo latinoamericano, figuran las obras de Rubén Darío, José Martí, Máximo Soto Hall, Paul Groussac o Eduardo Prado ( DEVÉS VALDÉS, 2000, p. 34).

Un problema central para estos pensadores que se posicionaron en ruptura con el positivismo, fue el naciente imperialismo del país del norte asentado en un cuerpo ideológico basado en el Destino Manifiesto y la Doctrina Monroe, que posibilitó la expansión de los intereses norteamericanos por la fuerza por el Caribe, Centroamérica y Asia ( BOSCH GARCÍA, 1986, p. 239). En especial, la declaración de guerra a España en 1989 impactó en la intelectualidad americana, acelerando un pensamiento crítico y creando una conciencia antiimperialista en América, Filipinas y también en Éspaña, con la generación del 98 ( BUELA, 2007). A la cabeza de esta reacción americana puede ubicarse entonces a José Enrique Rodó con su Ariel (1900) y Motivos de Proteo(1909). En oposición a las élites positivistas y modernizadoras, que planteaban a los Estados Unidos como modelo de desarrollo exitoso, estas nuevas miradas críticas lo situaban como el representante más acabado del espíritu utilitarista y mercantilista opuesto a toda posibilidad de desarrollo de una civilización espiritual, humanista y desinteresada, propia de una tradición latina.

En convergencia con estos reclamos identitarios también se posicionaron los idearios tradicionalistas propios de los partidos conservadores y de la jerarquía católica. El catolicismo proveyó un discurso de reivindicación de lo propio hispanoamericano, una tradicional oposición a lo extranjero, una oposición a la modernización y al capitalismo, que enriqueció y fortaleció las banderas identitarias de las distintas corrientes ideológicas de izquierda o de derecha, a lo largo del siglo.

Pero abordar la problemática de la historicidad, significa reflexionar acerca del problema de la circulación y recepción mediante el cual un cuerpo de ideas producidas en y para otros contextos, es leído, traducido, interpretado, apropiado, usado y discutido 
en suelo americano. Así, en el centro del problema de la recepción se ubican las disputas por la identidad y la diferencia, el desencuentro y el descentramiento que marcan el movimiento mediante el cual en el proceso cultural latinoamericano las ideas concebidas en otras latitudes en muchas casos fueron percibidas, no sin cierta fatalidad, como "impracticables y al mismo tiempo indispensables" (PALTI, 2002). Es justamente ese proceso el que da lugar a las múltiples querellas y debates que han cruzado la historia latinoamericana entre universalistas y criollistas, europeístas y nacionalistas, entre otros. Lo interesante es rescatar "cómo los autores extranjeros son leídos para (supuestamente) encontrarse los latinoamericanos a sí mismos” (DEVËS VALDES, 2000, p.40).

Para el momento de la aparición de Ariel de Rodó, el nuevo movimiento comenzaba a nutrirse de las filosofías europeas que se levantaban en oposición al positivismo imperante en Europa y de fuerte arraigo, con sus particularidades, en suelo americano. Los reclamos identitarios se nutrieron del despertar en Europa del vitalismo espiritualista que resaltaba la libertad creadora y un idealismo de raza y cultura. Los filósofos orientadores eran Henri Bergson, Benedetto Croce y Giovanni Gentile, MarieJean Guyau, Émile Boutroux, Arthur Schopenhauer, William James y Friedrich Nietzsche (PRO, 1965, p. 37). Insertos en el contexto de circulación de ideas a través de los viajes, los escritos y las redes de afinidades de los intelectuales, los nuevos paradigmas se fueron repitiendo, e influenciando el pensamiento latinoamericano que los utilizaba para reivindicar una manera de ser propia y diferente.

La recepción de estas nuevas ideas europeas fue posible en el contexto de la transformación del positivismo finisecular, que se caracterizó por la aceptación y la apertura hacia las humanidades. La generación uruguaya del novecientos a la que pertenece Rodó se hallaba a caballo entre dos siglos, lo que explica la condición ecléctica de sus producciones y la coexistencia de elementos propios del positivismo como la idea del progreso y la importancia de la ciencia y la educación, junto con la revalorización de las humanidades, el idealismo, la libertad creadora y el sentido estético y moral de la condición humana. En las obras de esta generación coexisten “elementos dispares, lo clásico y lo romántico, lo científico y lo místico, el revival y la utopía de futuro, lo autóctono y lo universal” (CASTRO MORALES, 1987-88, p. 129).

Revista Eletrônica da ANPHLAC, n.13, p. 204-226, jul./dez. 2012. http://revista.anphlac.org.br/index.php/revista 
José Enrique Rodó formado en el positivismo, no realizó una ruptura completa sino que, a partir de esa matriz intelectual y rescatando la ciencia, la razón, la crítica y el escepticismo, en la línea de la tradición racionalista e ilustrada, construyó un proyecto americanista fundado en la moral, la estética y el sentido cívico del individuo (ROJAS, 2012, p. 37). Este último aspecto, es justamente lo que lo llevó tempranamente a participar en la esfera pública, apoyando al Partido Colorado como diputado en diversos períodos entre 1902 y 1910. Su sentido positivista de confianza en el progreso de la civilización través de la educación, lo impulsó a participar en la elaboración de leyes para la solución de los problemas educativos, universitarios y de investigación, que posibilitaran una sociedad justa, democrática y culta (BEORLEGUI, 2006, p. 370). Sin embargo, como típico representante del intelectual "a caballo entre su labor académica y su presencia en la esfera pública” (BEORLEGUI, 2006, p. 369) mantuvo posiciones críticas e independientes hacia el mismo partido Colorado, lo que produjo su alejamiento de la política en diversas circunstancias y su voluntario exilio en Europa en 1916, muriendo en soledad un año después.

La influencia de Rodó también fue posible debido a su múltiple presencia como intelectual, político, crítico literario y periodista, siempre enarbolando un proyecto basado en la revalorización de la identidad americana pero con sentido universal y global. Fue un gran divulgador poniendo sus ideas en circulación tempranamente a través de diversas revistas culturales y literarias tales como la Revista Nacional de Literatura y Ciencias Sociales, la Revista de Salto, la Revista de Salto, Almanaque Artístico del Siglo XX y la colección La Vida Nueva entre otras. A través de las múltiples reediciones de sus obras en especial Ariel, el impacto de su obra se propagó profundamente entre los jóvenes intelectuales preocupados por la realidad latinoamericana tanto de Uruguay como de Argentina, Puerto Rico, Costa Rica, Ecuador, Venezuela, Perú, Cuba y México con Herníquez Ureña, Antonio Caso, José Vansconcelos y Alfonso Reyes (DEVÉS VALDÉS, 2000, p. 34, BOSCH GARCÍA, 1986, p. 258). Estos jóvenes pensadores buscaron la identidad de Latinoamérica en las características particulares de la cultura latina y las razas aborígenes, reforzando la unidad comunitaria para impedir la imitación y penetración extranjerizante, principalmente la norteamericana.

Revista Eletrônica da ANPHLAC, n.13, p. 204-226, jul./dez. 2012. http://revista.anphlac.org.br/index.php/revista 
La figura de Nimio de Anquín es por demás difícil de encuadrar ya que, en primer lugar, atravesó dos épocas convulsionadas del siglo XX: el mundo del ascenso de los nacionalismos totalitarios, la Guerra Civil Española y la II Guerra Mundial y, por otro lado, la Guerra Fría, el mundo bipolar, la Revolución Cubana y el origen de las agrupaciones armadas. En segundo lugar, porque este intelectual cordobés es altamente reconocido por su actividad filosófica, pero es denostado por su actividad política, encasillado en un nacionalismo católico intransigente y filo-fascista. En ambos períodos existieron ejes fuertemente vinculantes de su pensamiento político y filosófico: su catolicismo, su antiimperialismo, su nacionalismo y su aversión a la modernidad liberal y al comunismo.

Nimio de Anquín pertenece a la denominada generación de 1925, junto con Carlos Astrada (1894-1970), Luis Juan Guerrero (1890-1957), Raúl Scalabrini Ortíz (18981959), Alejandro Bunge (1880-1943), Francisco Romero, Tomás Casares (1895), Leonardo Castellani(1899), Ángel Virasoro (1900), Sixto Terán (1899), Alfredo Franceschi (1891-1942), Bernardo Ganáis Feijoo (1897), Ezequiel Martínez Estrada (1895) y Aníbal Ponce.

Desde 1925 la cultura filosófica argentina se caracterizó por su "originalidad y profundidad, haciéndose más crítica, de fuerte carácter académico y profesional" (BUELA, 2007). La generación de 1925 incorporó al pensamiento argentino la filosofía de Flusserl, Hartmann, Scheler, Simmel, Dilthey, Freyer, Heidegger, Kant, la filosofía de Hegel, la filosofía axiológica, el existencialismo germánico y el marxismo. La filosofía tradicional, con fuentes en santo Tomás, Francisco Suárez y Juan de Santo Tomás (PRO, 1965).

Pero lo más interesante al analizar las condiciones de producción y circulación del pensamiento de la generación del 25, es rescatar el valor de los viajes de estudio a las universidades europeas para realizar los doctorados, que posibilitaron la llegada de modo directo no sólo del pensamiento inglés y alemán, sino también las del pensamiento italiano, español y norteamericano. Como ejemplo, tenemos a Nimio de Anquín y a Carlos Astrada, ambos egresados de la Universidad Nacional de Córdoba, quienes viajaron con una beca a Alemania a realizar sus doctorados. Nimio de Anquín realizó sus estudios de posgrado en la Universidad de Hamburgo en 1927 y en 1950 recibió de la Universidad de Maguncia el doctorado honoris causa. Se rescata así, el

Revista Eletrônica da ANPHLAC, n.13, p. 204-226, jul./dez. 2012. http://revista.anphlac.org.br/index.php/revista 
impacto de la lectura y el trabajo sobre las fuentes mismas en sus idiomas originales y las traducciones para el mercado argentino. Por otro lado, estos viajes significaron el contacto con los autores y filósofos europeos y la conformación de relaciones y redes que llevaron a los intelectuales europeos a realizar viajes a Latinoamérica. Se destaca por su importancia continental, la magnitud y prestigio de los visitantes extranjeros, el Congreso de Filosofía realizado en Argentina en 1949, siendo uno de los principales organizadores Nimio de Anquín.

El contexto de recepción de estas nuevas corrientes filosóficas fue la crisis global de la matriz democrática liberal con el surgimiento de los totalitarismos europeos, la Guerra Civil Española y especialmente la ruptura que produjo la Segunda Guerra Mundial. La secuela de la crisis cultural europea, rompió en los pensadores la dependencia cultural con el viejo continente y los obligó a buscar en su propio pasado las claves de su identidad, descubriendo los rasgos peculiares de América Latina. Todos los pensadores de esta generación se comprometieron desde distintas vertientes ideológicas en esta búsqueda de la identidad latinoamericana y funcionaron como puente para la generación que irrumpió hacia los sesenta y setenta con nuevas proyectos a la luz de la Guerra Fría, el imperialismo norteamericano, la Revolución Cubana, la Teología de la Liberación y la Filosofía de la Liberación.

La mayoría de los enfoques historiográficos que tratan el fenómeno del nacionalismo, especialmente el nacionalismo católico de tipo integrista, encasillan a Nimio de Anquín en esta postura sin prestar atención a la complejidad y a las mutaciones de su postura filosófica y política que permite explicar su tránsito desde la idea de Cristiandad y la Nación Católica, hasta su adhesión al peronismo y en los años setenta a la agrupación política Montoneros. Por ello, en este trabajo se remarca que la trayectoria filosófica y política de Nimio de Anquín puede dividirse en dos etapas (BUELA, 2003).

La primera etapa, de inspiración tomista que cubrió las décadas del veinte, del treinta y principios del cuarenta, utilizó la topología histórica-metafísica y fundó en Córdoba, junto con su maestro Luis Martínez Villada y RodolfoMartínez Espinosa, José María Martínez Carreras, ClementeVillada Achával, Ascencio Viramonte Oliva y otros, el Instituto de estudios superiores Santo Tomás de Aquino (VERA DE FLACHS; SILLAU PÉREZ, 2009). Estos intelectuales aspiraban en lo político a un nuevo orden, 
que Nimio de Anquín definía como antiliberal, antirrenacentista y antiburgués. Basados en una concepción católica integralista, sostenían como proyecto político la idea de una nación católica (ZANATTA, 1999). Nimio de Anquín actuó como dirigente de organizaciones filo-fascistas como el Frente de Fuerzas Fascistas (1935), que en 1936 se denominó Unión Nacional Fascista. Sus simpatías políticas estaban más cercanas a los autoritarismos católicos de Oliveira Salazar o de Franco que al fascismo italiano y alejado del nazismo que consideraban pagano (VERA DE FLACHS; SILLAU PÉREZ, 2009). Sin embargo, concordaban con el discurso fascista especialmente en cuanto al anticomunismo, la crítica a la democracia liberal, el ataque al espíritu burgués, el antiimperialismo y la denuncia a la explotación capitalista hacia las clases trabajadoras.

A pesar de esta concepción católica intransigente, no era el factor religioso el eje decisivo en el proyecto político de Nimio de Anquín, sino el nacionalismo. A pesar de su adhesión al catolicismo, como peronista no apoyó a la Iglesia en el conflicto abierto que desembocó en la Revolución del 55 y, a diferencia de otros católicos nacionalistas amigos de él, Nimio no rompió con su apoyo a Perón y sufrió la exoneración de sus cargos docentes. Esta diferencia fue producto de la mutación en su concepción filosófica que lo llevó a sostener que la etapa de la Cristiandad estaba ya superada y que el devenir histórico era irreversible, siendo imposible una restauración de la misma.

El peronismo marcó profundamente la experiencia de muchos intelectuales y provocó cambios significativos en las diversas corrientes de pensamiento que adhirieron al mismo. Muchos filósofos "buscaron en su preguntar por el problema del ser y del ente, una explicación de ese (...) proceso de emergencia social y un pensamiento ajeno a las formas de saber opresivo" (ROIG, 2004). Especialmente en el caso que estudiamos, la emergencia del peronismo marca la segunda etapa en la filosofía y la política de este pensador cordobés (BUELA, 2003). Esta transformación implicó también una modificación de su proyecto político, abandonando toda ilusión de una nación católica y su adhesión al peronismo como nacionalismo popular $\mathrm{y}$ antiimperialista. Sin abandonar su concepción del ser latinoamericano como profundamente marcado por el catolicismo, este factor se vuelve instrumental, un factor de unidad cultural y espiritual. Bajo esta nueva perspectiva, a partir de la modernidad el orden social no se identificaba más con el orden sobrenatural sino con el natural. Fue en ese momento cuando Nimio de Anquín, bajo las influencias de las filosofías de las

Revista Eletrônica da ANPHLAC, n.13, p. 204-226, jul./dez. 2012. http://revista.anphlac.org.br/index.php/revista 
posguerras, elabora su ontología que se planteaba la cuestión del hombre americano y sentaba así las bases para una filosofía americana, convirtiéndose en uno de los puntos de partida para los filósofos de la liberación. Para Arturo Roig, "la problemática de la alteridad del ente en Nimio de Anquin intenta ser una respuesta a lo que entiende qué es la conciencia del hombre americano y las modalidades que ofrece en relación con el desarrollo de la modernidad europea" (ROIG, 2004). La prioridad de la conciencia natural del hombre americano con respecto al sobrenatural de las doctrinas teológicas, suponía para Nimio de Anquín, una regresión a la visión griega del mundo a partir del cual hay que entenderlo. No era posible ya un orden social adecuado a una mirada creacionista o teológica, ya que al igual que en occidente a partir de la modernidad, se había acontecido la muerte del eón cristiano. Esto no significa que Nimio de Anquín desdeñara la necesidad del catolicismo por "la respuesta radical que la tradición judeocristiana ofrece al problema de la alteridad, al distinguir de modo absoluto la naturaleza de las creaturas respecto de la del Creador" (ROIG, 2004).

Esta modificación con respecto a su postura anterior era, sin embargo, solidaria con el antiguo rechazo de la democracia liberal y al imperialismo norteamericano. Posición que coincidía con los movimientos nacional-populares que a partir de los años 1940 formularon proyectos de sociedades de masas inclusivos con desarrollo económico y político independiente de los centros de poder internacionales a través de una tercera posición e integración latinoamericana. Se plantearon propuestas en el continente de modernización económica con el surgimiento de organizaciones como la CEPAL que propusieron la necesidad de quebrar la dependencia económica frente al predominio económico de los Estados Unidos.

\section{Análisis de las obras Ariel de José Enrique Rodó y Mito y política de Nimio de Anquín: diagnósticos, problemas y proyectos identitarios}

Ambos ensayos tienen una estructura semejante, partiendo los autores de principios generales centrales en sus posturas filosóficas o políticas. A la luz de dichos principios realizan luego un análisis de los problemas centrales: la imitación de los Estados Unidos como modelo de desarrollo y el problema de la hegemonía e imperialismo de los Estados Unidos. Finalmente cierran con el planteamiento de 
proyectos o ideales que también se han ido desgranando a lo largo del texto y con una exhortación al deber y a la acción.

\section{El problema del imperialismo de los Estados Unidos y de la imitación cultural}

Tanto José Enrique Rodó como Nimio de Anquín estaban insertos en un contexto donde la preocupación por el desarrollo y la modernización eran problemas fundamentales. A fines de siglo XIX y principios del XX, las generaciones positivistas y la inserción en el mercado mundial habían abierto las puertas para un desarrollo explosivo en Latinoamérica. En tanto, la década del 1950 marcó las discusiones sobre el desarrollo económico de la posguerra y la influencia dominante a nivel mundial de la economía de los Estado Unidos, tratando los gobiernos latinoamericanos de crear modelos de desarrollo e industrialización que posibilitaran la independencia económica y la soberanía política.

Situados en dichos contextos históricos, ambos intelectuales asumieron que la superioridad de los Estados Unidos era irrefrenable a causa de su monumental riqueza, que le otorgaba una superioridad insuperable por cualquier país sudamericano. Por ello, estos autores no buscaron en la competencia material la posibilidad de frenar o contrarrestar esa dependencia, sino en el fortalecimiento de una identidad basada en lo cultural y espiritual como solución para la independencia política y autonomía espiritual. Rodó parado en el cambio del siglo, con el impulso de las filosofías vitalistas y las que enfatizaban el predominio de la voluntad, era más optimista con respecto a la posibilidad de revertir la influencia de los Estados Unidos. Al contrario, en Nimio de Anquín, subyace un pesimismo relacionado con la situación de dependencia económica, política y territorial en que había caído América Latina en la posguerra. Si en Rodó la educación era el instrumento y el camino para el desarrollo y progreso que se consideraba asequible, en Nimio era una exigencia ineludible para poder frenar el expansionismo norteamericano y rescatar los últimos resquicios de autonomía en el campo de la conciencia y el espiritual.

Ambos autores rechazaban la imitación de modelos extraños a la esencia e identidad del latinoamericano, cuya originalidad radicaba en su herencia occidental que combinaba el espíritu clásico griego y el catolicismo. Rodó rescataba el humanismo 
alegre y equilibrado del paganismo, en tanto Nimio de Anquín destacaba la concepción griega de la política y el Estado. El cristianismo aportaba para el intelectual uruguayo los conceptos de justicia, libertad e igualdad y para el filósofo argentino la conciencia de soberanía y fortalecía la unidad cultural y espiritual.

La crítica hacia los Estados Unidos era de tipo idealista, espiritualista y culturalista. Enrique Rodó definía a los Estados Unidos como la "encarnación del verbo utilitario" (representado en Calibán) que no cumplía con los requisitos de una civilización a la que aspiraba Latinoamérica de racionalidad y desarrollo de las exigencias del espíritu humanista (figura de Ariel) que aportaba dignidad intelectual y moral a la civilización. Por el contrario, sostenía que dicho país vivía para la realidad inmediata del presente, y por ello subordinaba toda su actividad "al egoísmo del bienestar personal y colectivo.” Por eso para el intelectual uruguayo, en Norteamérica predominaba la vulgaridad y no interesaba la "idealidad de lo hermoso" y de lo verdadero, menospreciándose todo pensamiento que no condujera a una finalidad útil.

Rodó mostraba que el impulso expansivo de los Estados Unidos basado en el impulso irrefrenable de la voluntad y de la acción, se había reflejado en la conquista del oeste americano y reclamaba la hegemonía más allá del propio territorio: "Hoy ellos aspiran manifiestamente al primado de la cultura universal, a la dirección de las ideas, $\mathrm{y}$ se consideran a sí mismos forjadores de un tipo de civilización que prevalecerá" (RODÓ, 1960, p. 70). Rodó prefiguraba y se oponía tempranamente al expansionismo norteamericano. Para el escritor uruguayo, el colosal progreso material de los norteamericanos era incompatible con el desarrollo de que caracterizaba a Latinoamérica que era el espíritu de Ariel: "en nombre de los derechos del espíritu, niego al utilitarismo norteamericano ese carácter típico con que quiere imponérsenos como suma y modelo de civilización" (RODÓ, 1960, p. 71, 72).

José Enrique Rodó incluso acusaba a los norteamericanos de haber corrompido lo único que habían tenido en su origen como paradigma para las demás naciones: la democracia, de la cual habían sido el ejemplo. Los Estados Unidos se habían transformado en una "plutocracia" manejada por aliados de los "trusts", monopolizadores de la producción y dueños de la vida económica. Por ello, el ensayista finalizaba este punto afirmando que:

Revista Eletrônica da ANPHLAC, n.13, p. 204-226, jul./dez. 2012. http://revista.anphlac.org.br/index.php/revista 
Una sociedad definitivamente organizada que limite su idea de la civilización a acumular abundante elementos de prosperidad, y su idea de la justicia a distribuirlos equitativamente entre los asociados, no hará de las ciudades donde habite nada que sea distinto, por esencia, del hormiguero o la colmena(...)(RODÓ, 1960, p.75)

Situado en 1955, muy lejos del optimismo de principios de siglo, Nimio de Anquín afirmaba en su ensayo Mito y Política, que la hegemonía en América había pasado a los Estados Unidos, adquiriendo plena vigencia la doctrina Monroe, y que así se desvanecía "el ensueño romántico de la doctrina argentina de "América para la humanidad" (DE ANQUÍN, 1956, p. 9). Desaparecido todo vestigio optimista de principios de siglo de la posibilidad del triunfo de Ariel, Nimio de Anquín sostenía que la unidad política de América no sajona ya no era por la hispanidad o por la latinidad, sino por el monroísmo y por la técnica que ha había contraído la unidad espacial de Latinoamérica. Europa solamente era el terreno de una futura "guerra inevitable", con la cual, sin embargo, había que mantener sus lazos culturales y espirituales.

Al igual que Rodó, el filósofo argentino sostenía que Estados Unidos era una plutocracia y que por eso era un gran imperio. Analizaba la relación de dominio entre Norteamérica que era "la Prosperity ("das Gedeihen")" y América sudcéntrica que era “el Estancamiento ("die Stagnation, die Stagnierung")" (DE ANQUÍN, 1956, p. 10). El dominio del norte se basaba en la fuerza, el poder de la economía y la supertécnica que se incrementaba en base a la expansión y explotación sobre los países de economía atrasada que se cada vez estaban más estancados. El autor de Mito y Política afirmaba así que los Estados Unidos con "su lema leviatánico, el Dominio hace la ley” era la superautoridad (DE ANQUÍN, 1956, p. 12).

Sin embargo en este pesimismo dejaba resquicios para formular la posibilidad de defensa de la propia identidad basada en la unidad espiritual que todavía no estaba subyugada por el país del norte. Esa unidad no existía porque la América sudcéntrica era cristianocatólica, mientras que la del Norte era protestante-calvinista y ambas orientaciones eran incompatibles. El catolicismo era una religión de pobres y humildes y, por lo tanto, si Norteamérica hubiera sido cristiana no poseería su fuerza material, pues cristianismo y poder material eran contradictorios (DE ANQUÍN, 1956, p. 9). Para Nimio, todo Estado rico y poderoso no podía ser cristiano. Por el contrario la tradición espiritual de América sudcéntrica la ligaba con Europa católica, y le imprimía 
características diferentes de los Estados Unidos que estaba regida -como también lo reconoció Rodó-, por una "voluntad de poder" que la erigió en superpotencia (DE ANQUín, 1956, p. 9, 10). Tanto para Rodó como para Nimio, el exceso de materialismo utilitarista era incompatible con el desarrollo de lo ideal, espiritual y humanista. En Rodó porque ese exceso de utilitarismo rompía el equilibrio que debía haber entre lo material y espiritual y, para Nimio de Anquín, porque en esencia, riqueza y espiritualidad eran incompatibles, siendo el cristianismo una religión de pobres y humildes. El catolicismo era el freno al imperialismo por proveer a Latinoamérica de una conciencia de unidad y soberanía política (DE ANQUÍN, 1956, p. 11).

\section{El problema de la democracia}

José Enrique Rodó y Nimio de Anquín, plantearon el tópico de la democracia como un problema central en la búsqueda de la identidad americana. En primer lugar, se oponían a la estrategia de los Estado Unidos que se erigía en el modelo de democracia que debía imitarse e instrumentarse. Este régimen político se presentaba así, como la fachada de la penetración cultural y política. Sin embargo la democracia adquiría para cada ensayista, distinto valor en la construcción de la identidad de América Latina.

En Rodó la democracia era sostenida como el mejor sistema pero diferente del que se desarrollaba en ese momento y especialmente en Norteamérica, donde la democracia -deformada-, representaba la antinomia de la civilización a la que aspiraba dicho intelectual. La degeneración del modelo de democracia, llevaba a la vulgaridad, la mediocridad y al igualitarismo chato del número por sobre la calidad (RODÓ, 1960, p. 64, 68). Rodó reivindicaba así a la democracia como modelo, pero con contenciones y límites. Si bien afirmaba que ella era para la civilización occidental un principio de vida contra el cual no había que rebelarse, sostenía que había que precaverse de los peligros de la "degeneración democrática, que ahoga bajo la fuerza ciega del número toda noción de calidad que desvanece en la conciencia de las sociedades todo justo sentimiento del orden" (RODÓ, 1960, p. 41). La democracia realizaba una obra de destrucción de las superioridades injustas de linaje o privilegios pero, a partir de la igualdad conquistada, debía ser un punto de partida para dar lugar a lo afirmativo, a lo constructivo de la democracia. Sin embargo, el uruguayo, con una mirada positiva creía posible a través de

Revista Eletrônica da ANPHLAC, n.13, p. 204-226, jul./dez. 2012. http://revista.anphlac.org.br/index.php/revista 
la educación instaurar en América latina, una democracia dirigida por los mejores (meritocracia) con el consentimiento libre de los iguales en derechos y oportunidades, pero desiguales en sus capacidades morales e intelectuales (RODÓ, 1960, pp. 50, 51, 52).

Por el contrario, en Nimio de Anquín la democracia liberal nacida de la Revolución Francesa era la causa de la dependencia de Latinoamérica y el dominio de los Estados Unidos (DE ANQUÍN, 1956, pp. 11, 12). El ideal democrático propuesto en Ariel por José Rodó era, para Nimio de Anquín un mito, un ente de razón, un modelo puro que no era posible aplicar. En Mito y Política, trataba de deslegitimar la democracia liberal que planteaba como el enemigo, porque anonadaba la conciencia de los pueblos que se dejaban avasallar y colonizar por los Estados Unidos. Rescataba en su ensayo, al Estado y a la democracia griegas como modelos naturales, que debían ser adaptados ya que no existían sistemas políticos puros e incorruptibles y, por lo tanto, debían cambiar de acuerdo a los tiempos históricos que eran irreversibles. Pero más allá de realizar la crítica de lo que denominaba el mito de la democracia liberal, no definía las formas y procedimientos que debía tener el sistema político deseable y adecuado a la Latinoamérica del momento.

Nimio de Anquín coincidía en que la democracia surgida de la Revolución había destruido las formas políticas medievales que ya estaban caducas y no tenían para qué perpetuarse, pero afirmaba que la democracia nunca había construido nada y nunca lo haría. Para Rodó, la autoridad vinculada al voto popular no debía basarse en el "sofisma de la igualdad absoluta" sino debía ser "la consagración de la jerarquía emanada de la libertad" (RODÓ, 1960, p. 42). Si bien tenía una mirada favorable hacia la Revolución Francesa porque había posibilitado el triunfo de la democracia y la consideraba la génesis de la independencia americana de España, rechazaba el jacobinismo al que llamaba "ferocidad igualitaria" y afirmaba que ese igualitarismo en "la forma mansa de la tendencia a lo utilitario y lo vulgar" (RODÓ, 1962, p. 45) era el objeto de real acusación a la democracia del siglo XIX. Esta crítica justamente era el núcleo de su rechazo a la democracia de Estados Unidos de fines de siglo, que había extinguido toda idea de superioridad dando lugar al predominio de la multitud sobre la calidad y dejando lugar a las luchas por el interés que era la forma "más innoble de las brutalidades de la fuerza." Coincidiendo con Rodó solamente en ese punto, Nimio de

Revista Eletrônica da ANPHLAC, n.13, p. 204-226, jul./dez. 2012. http://revista.anphlac.org.br/index.php/revista 
Anquín radicaba la crítica a la democracia en estas luchas por el interés. La democracia desataba la crisis porque se basaba en "la discusión no el raciocinio, ni la convicción, ni la persuasión, ni la decisión, ni la lógica; sino la dialéctica desenfrenada, la duda, la disuasión, la sofística, la erística y la confusión” (DE ANQUÍN, 1956, p. 12). En definitiva, era el reinado del Calibán de Rodó. Para Nimio de Anquín, la democracia debilitaba la voluntad y relajaba la energía creadora, llegando a calificarla como "opio democrático" culpable de que las naciones "sudcentroamericanas" no llegaran a tener instituciones permanentes y tuvieran "la conciencia anonadada bajo la sombra siniestra del Dominio" (DE ANQUÍN, 1956, p. 12).

Nimio de Anquín rechazaba a la democracia liberal porque era el imperio del individualismo y el olvido del orden y el bien común. Se oponía al liberalismo basado en la concepción griega del Estado, que era para él, el Estado natural y permanente, en donde el individuo era una parte del todo que era la sociedad: "el individuo pertenece al Estado, en cuanto éste es el todo y aquel la parte, porque cada parte, en cuanto tal es algo del todo y un hombre cual quiera es parte de la comunidad, y, por lo tanto, todo lo que él es pertenece a la sociedad" (DE ANQUÍN, 1956, p. 12). El orden perfecto era el Estado y la Sociedad, a la cual el individuo -que era lo imperfecto- se ordenaba. El bien de la Sociedad era "más divino que el bien singular" (DE ANQUÍN, 1956, p. 2). Nimio de Anquín sostenía que esa era la doctrina clásica del Estado heredada de los griegos, expuesta por Aristóteles en su Política y transcripta por Santo Tomás en sus comentarios. Es evidente que esta concepción difería de la liberal, ya que para ésta el individuo y sus derechos eran anteriores y tenían prioridad con respecto a la sociedad y al orden. De forma más rotunda, afirmaba que la democracia liberal no "cupo en las categorías de la filosofía y de la política clásicas. Para Platón, Aristóteles y Santo Tomás de Aquino la democracia liberal fue un no-concepto, un impensable" (DE ANQUín, 1956, p. 5). Por lo tanto, la única democracia posible era la no liberal. La democracia liberal era obra de la Revolución Francesa y no correspondía a lo natural, era un mito secular, un sustituto que reemplazó la pérdida de la identificación con lo sagrado, tomando como real un ente de razón.

\section{Dos proyectos identitarios para América Latina}

Revista Eletrônica da ANPHLAC, n.13, p. 204-226, jul./dez. 2012.

http://revista.anphlac.org.br/index.php/revista 
José Enrique Rodó, al oponerse a los Estados Unidos como modelo de civilización, realizaba un llamado a la juventud para que prepararan "el advenimiento de un nuevo tipo humano, de una nueva unidad social, de una personificación nueva de la civilización” (RODÓ, 1960, p. 79). Los jóvenes debían ser los precursores y agentes del cambio, utilizando como instrumentos o medios a la democracia y a la ciencia. Como faros en ese camino estaban los dos impulsos históricos que habían impreso a la civilización americana sus caracteres esenciales: el cristianismo que proporcionó el sentimiento de igualdad y la herencia de las civilizaciones clásicas, de las que nacieron el sentido del orden, de la jerarquía, el respeto religioso del genio y la conciencia de lo bello. La obra de la juventud era reconciliar el ideal cristiano "con la serena y luminosa alegría de la antigüedad” (RODÓ, 1960, p. 33). Para ello debían los jóvenes propagar y defender el ideal desinteresado del espíritu, el arte, la ciencia, la moral, la sinceridad religiosa, la política de ideas y educar su voluntad en el culto perseverante del porvenir.

La democracia y la ciencia debían ser la base del desarrollo de la igualdad de oportunidades para que, a partir de allí, se lograra la selección de los mejores dirigentes para llevar a cabo las transformaciones necesarias. El deber del Estado era dotar a todos los ciudadanos de igualdad de oportunidades para lograr su perfeccionamiento. De esta manera la igualdad democrática era el ambiente ideal para el desarrollo de la cultura, el más eficaz instrumento para la selección espiritual y para establecer la superioridad de los mejores, asegurándola sobre el consentimiento libre de los ciudadanos. La concepción cristiana aseguraría que la superioridad moral fuera un motivo de deberes que obligara a realizar el bien y fuente de orden estable (RODÓ, 1960, p. 50).

La democracia y la ciencia se transformarían así, en los dos insustituibles soportes de la civilización latinoamericana. Contra la crítica de la democracia como la causante de la mediocridad, la vulgaridad y el triunfo de la masa, Rodó planteaba que "sólo cabe pensar en la "educación" de la democracia y su reforma" (RODÓ, 1960, 48). En ese sentido, era imprescindible la educación popular que se convertía en el eje de la acción. La escuela en la que se transformaba a la muchedumbre en ciudadana, era el lugar de la equidad social, en donde se brindaba la igualdad de oportunidades y acceso a la civilización. Por ello se debía moldear a las multitudes a través de la educación basada en el sentido del orden, la idea y la voluntad de justicia, el sentimiento de las legítimas 
autoridades morales. Y allí radicaba, para José Enrique Rodó, la originalidad y el futuro de Latinoamérica, asentado en la armonía entre la actividad utilitaria y la ideal, frente al vulgar utilitarismo y expansionismo material de los norteamericanos, vacío de todo sustento espiritual. Como ejemplo y guía de la juventud en ese camino a conquistar, Rodó erige la figura de Ariel:

(...) afirmado primero en el baluarte de vuestra vida interior, Ariel es lanzará desde allí a la conquista de las almas. Yo le veo, en el porvenir, sonriéndoos con gratitud, desde lo alto, al sumergirse en la sombra de vuestro espíritu. Yo creo en vuestra voluntad, en vuestro esfuerzo; y más aún, en los de aquellos a quienes daréis la vida y transmitiréis vuestra obra. Yo suelo embriagarme con el sueño del día en que las cosas reales harán pensar que la cordillera que se yergue sobre el suelo de América ha sido tallada para ser el pedestal definitivo de esta estatua, para ser el ara inmutable de su veneración (...) (RODÓ, 1960, p. 85)

La preocupación central de la obra de Nimio de Anquín era el antiimperialismo y las formas de oponerse al mismo. Para ello analizó en Mito y Política las consecuencias internas de dicho imperialismo y los conflictos que generaba en cada país. Nimio de Anquín afirmaba que el dominio y la explotación del imperio norteamericano llevaban a la impotencia que derivaba, a su vez en dos actitudes posibles: en resignación y por lo tanto al "anonadamiento de la conciencia desdichada", o a la desesperación que conducía a la Revolución. Pero esta revolución no se dirigía contra el imperio sino que derivaba en guerra interna, civil y por lo tanto en autodestrucción. Ambos reacciones favorecían el dominio de los Estados Unidos: "es la dialéctica del señor y del siervo, pero en que éste o es esclavo envilecido que está anonadado, o aparece entregado a la autodestrucción en el círculo fatal de su impotencia desesperada" (DE ANQUÍN, 1956, p. 11). Ante esta situación, el filósofo proponía la necesidad de redirigir la revolución contra el imperio, hacia fuera en vez de contra sí misma, desencadenando la resistencia revolucionaria de Latinoamérica. Pero al ser los Estados Unidos invencible materialmente, esta revolución debía ser espiritual y para ello el primer factor que debía ser eliminado era la democracia que era "factor de crisis", y por lo tanto de “mediatización al Dominio" (DE ANQUÍN, 1956, p. 11). La base de esta revolución espiritual era actualizar el catolicismo que implicaba "re-crear su conciencia anonadada

Revista Eletrônica da ANPHLAC, n.13, p. 204-226, jul./dez. 2012. http://revista.anphlac.org.br/index.php/revista 
y con ello, su personalidad”. El medio era reintroducir la enseñanza de la religión en el sistema educativo: “el Cristianismo es un Imperativo de Occidente, en cualquier caso. Y por ello la enseñanza de la religión en las escuelas de Occidente debe ser necesariamente cristiana" (DE ANQUÍN, 1956, p. 13) y católica. Lo más interesante y que diferenciaba su postura de los tradicionalistas, era que su reclamo de la necesidad de la enseñanza cristiano-católica, no era porque ésta fuera más verdadera, sino porque era "la más conveniente, eficaz y útil" (DE ANQUíN, 1956, p. 13). Postulaba como base para la unidad latinoamericana la expansión del catolicismo a través de la educación como instrumento para desarrollar la conciencia soberana del continente. Centralmente, para el filósofo cordobés la importancia de lo religioso en Latinoamérica radicaba en que la profundización y expansión del catolicismo implicaba el "alejamiento mayor del espíritu protestante-calvinista, y consecutivamente a una mayor posibilidad de independencia política" (DE ANQUÍN, 1956, p. 10). Era, por lo tanto, una utilización estratégica de lo religioso más allá de su verdad intrínseca, era el terreno en que podía competir con los Estados Unidos y sostener una autonomía e independencia espiritual que la mantuviera soberana. De esta manera el catolicismo era útil porque en primer lugar, posibilitaba la permanencia de la conciencia de soberanía política y, en segundo lugar, como negaba el culto a la voluntad de poder, impedía "todo sueño imperialista" (DE ANQUíN, 1956, p. 10). Nimio de Anquín sostenía la imposibilidad de la fraternidad universal y sostenía que la amistad en el orden internacional era falaz porque la igualdad y la reciprocidad entre los grandes y pequeños eran imposibles. Por ello debía realizarse la Revolución espiritual contra el "dominio" para mantener la independencia espiritual y la voluntad de soberanía política de la “América sudcéntrica” (DE ANQUÍN, 1956, p. 11).

El perfil internacional característico de Latinoamérica era, justamente, su independencia espiritual y la voluntad de su soberanía política y sus lazos originarios con Europa. En ese sentido no puede catalogarse a Nimio de Anquín en el ensayo Mito y Política, como un tradicionalista que pretendía conservar las instituciones antiguas e implantar formas políticas caducas similares a la Edad Media. Por el contrario, este texto funcionó como la bisagra en su transformación filosófica, en la que abandona la posibilidad de la restauración de una "cristiandad", reconociendo el fin del "eón cristiano" y el predominio del hombre secular de la modernidad. Pero en una posición 
acorde con el catolicismo y los nacional-populismos en un mundo bipolar de la guerra fría, apoyó una tercera posición ni capitalista, ni comunista, que eran los dos polos del “Dominio" imperialista (DE ANQUÍN, 1956, p. 11).

Nimio proponía la unidad espiritual y cultural como base de la soberanía e independencia de Latinoamérica, frente al dominio de los Estados Unidos. Para lograr esta unidad en primer lugar intentaba en su ensayo, desarmar el "mito" de la democracia liberal como modelo político afirmando que, por el contrario, era causa de crisis, de anonadamiento de la conciencia e instrumento de dominación del imperio. El filósofo no planteaba ningún sistema político en especial sino que sostenía que todos eran instrumentales y debían adaptarse a cada contexto temporal e histórico. Finalizó su opúsculo con una demanda fuerte y un anhelo:

\begin{abstract}
Y será reo de traición a la Patria quien proponga o instituya un régimen político que signifique la mediatización del Estado argentino, o que establezca la posibilidad de que caiga bajo el imperio de cualesquiera de los extremos en que se polariza el Dominio. Pero el Estado argentino no puede ser democrático-liberal, pues si se intentara investirlo de esta forma de gobierno, sería fatalmente "un gobierno de crisis" y mediatizable: caería inmediatamente en el proceso de la revolución auto destructora. Argentina debe ser republicana, pero el republicanismo no debe ser entendido como un pluralismo libre, sino como un uniplurismo, es decir, como una totalidad ejecutiva que permita la convivencia de las partes en el servicio del Bien Común, fin objetivo le la Política. (DE ANQUíN, 1956, p. 13)
\end{abstract}

\title{
Conclusión
}

José Enrique Rodó y Nimio de Anquín, fueron dos intelectuales que representan en la historia del pensamiento latinoamericano, dos momentos centrales en contextos históricos de especial complejidad. Ambos enfrentaron el problema de la expansión e imperialismo norteamericano con la búsqueda de una identidad latinoamericana, el surgimiento de un hombre nuevo y una nueva civilización, basados en propuestas de unidad espiritual y cultural del continente. Tanto José Rodó como Nimio de Anquín, contraponían a la sociedad norteamericana, la "esencia latinoamericana" de raíces occidental-cristianas y que abrevaba en dos fuentes, la clásica griega y el catolicismo. Oponían así, la racionalidad y lo ideal al irracionalismo utilitarista y pragmático de los Estados Unidos. Rodó recurrió para simbolizar esta oposición, a las figuras de Ariel, encarnación de la razón, el sentimiento y lo espiritual, opuesto a Calibán, encarnación 
de lo vulgar y lo irracional. Nimio de Anquín, por otro lado, contrapuso el Mito político de la democracia liberal de los Estados Unidos que era la irracionalidad, a lo racional de las concepciones clásicas del Estado griego. Sin embargo estos intelectuales lucharon a partir de estos modelos occidentales, por la creación de nuevo modelos políticos sociales propios y originales para América Latina. Por ello ambos fueron inspiración para formulaciones filosóficas o políticas de distinta orientación, desde la derecha o la izquierda, que propusieron la emancipación Latinoamericana. Los problemas e inquietudes planteados desde la escritura del Ariel, y de Mito y Política, continúan vigentes en el desarrollo presente del continente americano, configurando los discursos y prácticas de los distintos actores político-sociales que pretenden un destino de autonomía para Latinoamérica, intentando armonizar modernidad e identidad.

\section{Referencias Bibliograficas}

ACOSTA, Yamandú. Historia de las ideas e identidad, Estudios de Filosofía Práctica e Historia de las Ideas. Vol. 11, $\mathrm{n}^{\circ}$ 1, Mendoza, Julio 2009, pp. 33-43, disponible en www.estudiosdefilosofia.com.ar

ALTAMIRANO, Carlos. Bajo el signo de las masas (1943-1973). Tomo VI, Biblioteca del Pensamiento Argentino, Buenos Aires: Ariel Historia, 2001

BEORLEGUI, Carlos. Historia del pensamiento latinoamericano. Una búsqueda incesante de la identidad. Bilbao: Universidad de Deusto, 2006

BIAGINI, Hugo Edgardo; ROIG, Arturo Andrés (directores). El Pensamiento Alternativo en la Argentina del Siglo XX: Obrerismo, vanguardia, justicia social (19301960), Tomo II. Buenos Aires: Editorial Biblos, 2006

BOSCH GARCÍA, Las ideologías europeístas. In: ZEA, Leopoldo (coord.). América Latina en sus ideas. Unesco, Siglo XXI editores, 1986.

BUELA, Alberto. Nimio de Anquín: entre el Ser y la Patria, (en línea), disponible en http://www.pensamientonacional.com.ar, 2003.

. Despliegue del Pensamiento americano (esquema para estudiar su desarrollo), Co-herencia, enero-julio, año/vol. 4, no 006. Medellín: Universidad Eafit, Colombia, 2007. Disponible en http://redalyc.uaemex.mx

Revista Eletrônica da ANPHLAC, n.13, p. 204-226, jul./dez. 2012. http://revista.anphlac.org.br/index.php/revista 
CASTRO MORALES, Belén. Eclecticismo y Modernismo (en J.E. Rodó y su generación), Revista de Filología. Universidad de La Laguna, no 6 y 7, 1987-88, 119130

DEVÉS VALDÉS, Eduardo. El pensamiento latinoamericano en el siglo XX. Entre la modernización y la identidad, Del Ariel de Rodó a la CEPAL (1900-1950), tomo I. Buenos Aires: Biblos, 2000.

DE ANQUIN, Nimio. Mito y Política. Córdoba: Ediciones Arkhe, 1956. Disponible en http://www.statveritas.com.ar/Libros/Libros-INDICE.htm

GONZÁLEZ CALLEJA, Eduardo. El Hispanismo autoritario español y el movimiento nacionalista argentino: balance de medio siglo de relaciones Políticas e intelectuales (1898-1946), Hispania, Revista Española de Historia, 2007, vol. LXVII, núm. 226, mayo-agosto, págs. 599-642

HALPERIN DONGHI, Tulio. La Argentina y la Tormenta del Mundo. Buenos Aires: Siglo XXI Editores, 2004.

MALLIMACI, Fortunato. Nacionalismo católico y cultura laica en Argentina. In: BLANCARTE, Roberto (coordinador). Los retos de la laicidad y la secularización en el mundo contemporáneo. México: El Colegio de México, 2008. Disponible en http://www.ceil-piette.gov.ar/investigadores/fmallimacipub/2008cnaci.pdf . Las paradojas y las múltiples modernidades en Argentina. In: Fortunato Mallimaci (comp.): Modernidad, religión y memoria. Buenos Aires: Colihue, 2008. Disponible en http://www.ceil-piette.gov.ar/investigadores/ fmallimacipub /2006 areli.pdf

PALTI, Elías José. El problema de "las ideas fuera de lugar" revisitado. Más allá de la "historia de ideas, Seminario de Historia Intelectual, México: El Colegio de México, 2002. Disponible en: http://shial.colmex.mx/textos/EliasPalti-Enero2002.pdf

PRO, Diego. Periodización del pensamiento argentino, (en línea). Tomo_01_Cuyo_1965. Disponible en http://www.ffyl.uncu.edu.ar/IMG/pdf/8_ _tomo_01.pdf.

PUIGGRÓS, Adriana (dir.). Peronismo: cultura política y educación (1945-1955), Historia de la educación argentina, tomo V. Buenos Aires: Galerna, 2006.

RODÓ, José Enrique. Ariel, México: Biblioteca del Maestro, CAPFCE, 1960. 
ROJAS, Rafael. El lenguaje de la juventud. En diálogo con Ariel, de José Enrique Rodó, Nueva Sociedad No 238, marzo-abril de 2012, ISSN: 0251-3552, disponible en $\mathrm{http} / /$ www.nuso.org

ROIG, Arturo Andrés. Teoría y crítica del pensamiento latinoamericano, edición digital, disponible en http://www.robertexto.com/archivo2/roig8.htm , 2004

TCACH, César. La derecha ilustrada: Carlos Ibarguren, Nimio de Anquín y Lisardo Novillo Saravia (H), Estudios Digital, nº II, Centro de Estudios Avanzados, UNC, 2009. Disponible en http://www.revistaestudios.unc.edu.ar/articulos02/articulos/tcach.php.

VERA DE FLACHS, Maria Cristina. Reformas, contrarreformas y movimientos estudiantiles en la Universidad de Córdoba (1870 -1936). In: MARSISKE, Renata; ALVARADO, Lourdes. Movimientos estudiantiles en la historia de América Latina, T. 3. México: Plaza y Valdés, 2006, pp. 21- 80. ; SILLAU PÉREZ, Antonio. Ideología y Política Docentes y Estudiantes en el Contexto de La Crisis Liberal Argentina El caso de la Universidad de Córdoba (1930-1943). Revista Historia de la Educación Latinoamericana, nº 12, Tunja: Universidad Pedagógica y Tecnológica de Colombia, 2009, pp. 247 - 273

ZANATTA, Loris. Perón y el Mito de la Nación Católica. Iglesia y Ejército en los orígenes del Peronismo, 1943-1946. Buenos Aires: Editorial Sudamericana, 1999.

Revista Eletrônica da ANPHLAC, n.13, p. 204-226, jul./dez. 2012. http://revista.anphlac.org.br/index.php/revista 